\title{
Some Comments on John W. Reid's Paper
}

\author{
by Luigi Selleri*
}

John W. Reid introduces in his paper the new concept of risk partnership, which represents a new concept for insurers and insureds. Reid's position is, in our opinion, in line with the new orientations of risk management.

The role of risk management is no longer limited to the integrated management of pure risks but must be referred to a company's vulnerability. In fact, the changes in the environment and market where companies operate puts into evidence the limits of a risk management aimed exclusively at the integrated management of pure risks and requires logically a management of a company's global system of risks. We can observe the need at the company level of an integrated management of both external sources of risks (environmental and market developments, disrupting events, effects by "force majeure" or third parties) as well as internal sources of risks (mistakes or malicious acts by employees, technical failure, inefficiencies and deficiencies in the structure and behaviour of the company). This is a new strategic dimension to risk management and, consequently, the top management responsibility for it.

This strategic dimension of risk management points to the need to define a new model of risks assessment. The present model aims to reduce the economic impact of pure risks on the company, that is to reduce the cost of risk. The new concept aims to contain the vulnerability of a company within levels compatible with the company's survival and development.

As vulnerability reduction requires resources, which are always limited in a company, top management must carry out a comprehensive assessment of global risks in order to estimate different costs which could be sustained with regard to different levels of vulnerability. In this context, it is necessary to identify trades-off between benefits obtainable from the reduction of vulnerability levels, and the costs of alternative action plans. These evaluation will be difficult with regards to costs; only few may be measured in monetary terms, whereas others may require opportunity cost estimates. Benefits can equally be measured in monetary terms (increasing value added, decreasing value deducted), through indicators (impact of business interruption on the relations with customers, suppliers, financial intermediaries, other companies, and so on) or through qualitative evaluations (the impact on the image and on the reputation of the company, and so on).

Top management thus needs models which enable it to integrate cost and benefit evaluations relating to different vulnerability levels, and to decide the level of security that needs to be achieved. This level defines the maximum loss sustainable, or MLS, that is the largest loss that a company may bear without reducing its competitive advantage below a level required in order to achieve its objectives.

Designing and implementing these models requires time and resources, but it is the only way to correctly and constructively manage the vulnerability of companies. We can therefore expect an increasing attention to research in this field in the coming years.

* Professor at Università Catholica, Milano, Italy. 